\title{
The Effect of Life Skills Training on the Mental Health and Level of Resilience among Teachers of Normal Students and Teachers of Exceptional Students in Zahedan
}

\author{
Hossein Jenaabadi ${ }^{*}$, Bahareh Azizi Nejad², Rozita Mostafapour ${ }^{3}$, Rezvan Haghi ${ }^{4}$ \\ ${ }^{1}$ Department of Education, University of Sistan and Baluchestan, Zahedan, Iran \\ ${ }^{2}$ Department of Educational Science, Payame Noor University, Urmia, Iran \\ ${ }^{3}$ Tabriz Azad Islamic University, Urmia, Iran \\ ${ }^{4}$ Allameh Tabatabayi University of Tehran, Tehran, Iran \\ Email: "hjenaabadi@ped.usb.ac.ir
}

Received 29 October 2014; accepted 23 November 2014; published 16 February 2015

Copyright (C) 2015 by authors and Scientific Research Publishing Inc.

This work is licensed under the Creative Commons Attribution International License (CC BY). http://creativecommons.org/licenses/by/4.0/

c) (i) Open Access

\section{Abstract}

This is an experimental study conducted on two groups of control and experimental using pretestposttest design, applying psychological intervention on the study sample. The present study aimed to determine the effectiveness of collective education life skills on mental health and resilience of teachers in Zahedan. The population of the study included all teachers at schools with normal students and teachers at schools with exceptional students in Zahedan, among which 60 teachers at normal schools and 20 teachers at exceptional schools were selected and placed in two groups of experimental and control, respectively. Initially, members of the experimental group were taught 10 basic life skills in 10 2-hour sessions. Mental health and resilience questionnaires were distributed and gathered before and after the training sessions. Results indicated the positive effect of life skills training on mental health of teachers at schools with normal students and teachers at schools with exceptional students, which meant that the more the life skills training to teachers at schools with normal students and teachers at schools with exceptional students, the lower their mental health scores would be. Results also indicated the positive effect of life skills training on resilience of teachers at schools with normal students and teachers at schools with exceptional students, which meant that the more the life skills training to teachers at schools with normal students and teachers at schools with exceptional students, the higher their resilience scores would be.

${ }^{*}$ Corresponding author.

How to cite this paper: Jenaabadi, H., Nejad, B.A., Mostafapour, R. and Haghi, R. (2015) The Effect of Life Skills Training on the Mental Health and Level of Resilience among Teachers of Normal Students and Teachers of Exceptional Students in Zahedan. Open Journal of Medical Psychology, 4, 17-22. http://dx.doi.org/10.4236/ojmp.2015.42002 


\section{Keywords}

\section{Life Skills Training, Mental Health, Level of Resilience, Teachers of Normal Students, Teachers of Exceptional Students}

\section{Introduction}

One of the most important factors that help people live well and successfully is to know and feel good about themselves. Life skills help individuals understand more about themselves, their characteristics, needs, desires, goals, weaknesses, strengths, passions, values and identity (Fati et al. [1]).

Nowadays, one of the most important indicators of development in all countries is the health level of the community. Lazarus believes that mental health is the individual's mental capacity to effectively, harmoniously, pleasantly and flexibly operate in difficult situations and to maintain a balance (Ganji [2]).

Taghavi (2001) considers mental health encompassing 4 components of somatic symptoms disorder, anxiety and sleep disorder, social dysfunctioning and depression symptoms. Briefly, somatic symptoms include headache, faint, the need for nutritional medication, and feeling hot or headaches. Mental balance depends on several factors, the most important of which are the feeling of security and value, lack of anxiety and depression, high social functioning and physical health and vitality. People who suffer from neurological and psychological problems are anxious, depressed, lost, and aimless, and the continuity of such situations may cause mental illness. Research indicate the prevalence of a variety of psychiatric disorders, including anxiety, stress and depression in today's society, so that many people suffer from these problems and enormous costs are spent annually to treat these disorders (Milanifar [3]).

The positivist approach to psychology, based on human being's talents and abilities (instead of dealing with anomalies and disorders), has attracted psychologists' interest in recent years. This approach aims to identify constructs and methods that imply well-being and happiness of human beings. Accordingly, factors that lead to greater adaptability of humans to needs and threats of life constitute the fundamental structures of this approach. Hence, resilience has a special position in the field of psychology, evolution of family psychology and mental health, so that each day the number of studies related to the structural resilience increases. Resilience is defined as a process, ability, or the outcome of successful adaptation to threatening conditions.

In other words, resilience is the positive adaptation in response to adverse conditions; however, resilience is not only a resistance against trauma or threatening condition or a passive state against dangerous conditions, but also an active and constructive engagement in the environment. It can be claimed that resilience is an individual's ability to establish biological-mental balance, a kind of self-relieve with positive emotional, affective and cognitive consequences. Garmezy (1991), Mastan (2001), Rotter (1999) and Luther, Cicchetti and Becker (1999) believe that resilience is the reestablishment of the initial balance or striking a higher level of balance in threatening life conditions and thus provides the successful adaptability in life. However, Kampfer also notes that positive adjustment to life can be considered as both the consequence of resilience and its cause. He considers the issue as the result of complexity and process-oriented view toward resilience (Samani, Jokar and Sahragard [4]).

Given the central role of life skills training on resilience and mental health, this study seeks to answer the following question:

Does life skills training have any significant effect on resilience and mental health affect teachers at schools with normal students and teachers at schools with exceptional students?

Bob and Roisin [5], investigating students' communication skills, conclude that these skills dramatically increase students' self-confidence and communication skills and flexibility. Bo et al. [6], examining the quality of life among rural migrants in cities, conclude that teaching life skills to immigrants before the migration, with a focus on efficient coping skills, improves their quality of life and mental health.

Martin and Jones [7] claim that personal skills, discipline, performance results management and self-confidence are among the most important life skills. In another study conducted by Turner et al. [8], studying life skills training, such as problem solving and effective communication on adolescents, indicates that these skills increase their abilities to solve problems and effectively use social support.

Tuttle et al. [9] add specific cognitive skills as positive life skills to students' curriculum and examine the in- 
teractions among them. Results indicate that adolescents' extraordinary ability improves their positive flexibility. In a case study, Matsuda and Schiyama (2006) examine assertiveness social skills training among 4 patients with psychosomatic disorders and mental disorders. The mentioned training includes relieving behaviors to soothe muscle tension and positive behavioral eclectic skills.

Johnson and Johnson [10] considered the following results as the beneficial effects of social skills training: 1) Individual and identity development; 2) Job opportunities; 3) Improving the quality of life; 4) Physical health; 5) Mental health; 6) The ability to cope with anger-provoking situations.

Harter [11] argues that there is a relationship between decreased permanent self-esteem and decreased academic progress, depression, eating disorders and delinquency, and that social skills training causes reduction of anxiety of female students. Lewis and Timothy (1998) conclude that social skills training programs lead to reduced anti-social behavior and problematic behaviors.

Binetand Schneider (1995, as cited in Lieberman, 1998) conclude that social skills training leads to increase the understanding of social self and decrease in negative behaviors toward peers and provides ability and quality of the behavior.

In 2011, Rahmanpour et al. [12] conducted a research study on the effect of life skills training on self-esteem and mental health and found that life skills training led to mental health and self-esteem.

Pourseyed et al. [13] suggest that life skills training leads to an increase in the experimental group' blind and visually impairs students' adaptability compared with the control group. They calculate the reliability factor of the questionnaire under the study 0.85 .

Jalili Abkenar [14] in a study entitled "The Effect of Social Skills Training on Hearing Impaired Students" conclude that teaching social skills, communication techniques, helping students about making friends and informing families lead to relatively facilitate the acceptance by peers and their social development and consequently their vitality and freshness and health are secured.

Sajedi et al. [15], examining the effect of life skills training on interpersonal relationships, self-esteem and assertiveness of blind girls, find that life skills training has a significant effect on self-esteem $(p<0.001)$. However, it does not have any significant effect on interpersonal relations $(p<0.05)$. Moreover, the comparison of the mean scores of the two groups of experimental and control indicated that controlling pretest scores, the mean scores of the self-esteem posttest and assertiveness for the experimental group were higher than those for the control group. He estimated the reliability using the Cronbach's alpha. The reliability of Alberti and Emmons's Assertiveness Scale was 0.88 , for Rosenberg's self-esteem scale, the reliability was 0.81 , and for the subscale of interpersonal relationships, the reliability was 0.82 . Ahadi [16], examining the effect of social problem solving on social adaptation and performance of shy children, conclude that enriching the social environment in terms of social problem solving skills can lead to the formation of social adaptability. This researcher obtained the reliability coefficient of the Shyness Scale 0.89 and social compromise reliability coefficient as 0.68 which indicated appropriate internal consistency of the scales.

\section{Research Method}

The present study was conducted on two groups of control and experimental using pretest-posttest design applying psychological intervention on the study sample. The current study aimed at determining the effectiveness of collective education life skills on mental health and resilience of teachers in Zahedan.

The population of the study consisted of all teachers at schools with normal students and teachers at schools with exceptional students in Zahedan, among which 60 teachers at schools with normal students and 20 teachers at schools with exceptional students were selected and placed in two groups of experimental and control, respectively.

\section{General Health Questionnaire (GHQ-28)}

Goldberg (1979) devised a 28 -item mental health questionnaire (GHQ-28) as the most known screening tool to evaluate psychiatric and mental health status. The 28 -item form used in the present study includes four subscales each having seven items measuring four categories of non-psychiatric disorders, including 1) somatic symptoms; 2) anxiety and sleep disorders; 3 ) social dysfunctioning; 4) depression and suicidal tendencies. Items of each subscale are presented in order. In this regard, items 1 to 7 relate to somatic symptoms, items 8 to 14 associate with anxiety and sleep disorder, 15 to 20 relate to social dysfunctioning and finally items 22 to 28 relate to de- 
pression. The questionnaire scores based on a four-point Likert scale from 0 to $3(0=$ never; $1=$ usually; $2=$ more than usual; 3 = much more than usual). Therefore, high scores indicate the severe state of the subject. The overall score of the questionnaire indicates subjects' general health.

\section{Resilience Scale (RSA)}

To measure the resilience the Fribourg resilience scale was used. The scale has 43 five-point Likert-scale type items from $1=$ strongly disagree to $5=$ completely agree. Higher scores indicate lower resilience. The minimum and maximum scores of the test are 43 and 215, respectively. In this study, the Persian version of the scale was used. Chalmeh reported the validity of the Persian version using factor analysis. In addition, Nour Afshan reported the Cronbach's alpha reliability value of the scale was 0.91 .

To analyze the data T-test was used.

H1: Life skills training has a significant effect on resilience of teachers at schools with normal students.

Table 1 indicates that post-test scores (173.17) of the experimental group increased significantly comparing to pretest scores $(160.12)$. Calculated $\mathrm{t}(\mathrm{t}(58)=10.35)$ is statistically significant at $99 \%$ level. This indicates that the level of resilience of teachers at schools with normal students is affected by life skills training.

H2: Life skills training has a significant effect on resilience of teachers at schools with exceptional students.

Table 2 indicates that post-test scores (169.19) of the experimental group increased significantly comparing to pretest scores $(152.08)$. Calculated $\mathrm{t}(\mathrm{t}(18)=15.12)$ is statistically significant at $99 \%$ level. This indicates that the level of resilience of teachers at schools with exceptional students is affected by life skills training.

H3: Life skills training has a significant effect on mental of teachers at schools with normal students.

Table 3 indicates that post-test scores (16.73) of the experimental group decreased significantly comparing to pretest scores $(22.60)$. Calculated $t(t(58)=2.37)$ is statistically significant at $99 \%$ level. This indicates that the level of mental health of teachers at schools with normal students is affected by life skills training.

H2: Life skills training has a significant effect on mental health of teachers at schools with exceptional students.

Table 4 indicates that post-test scores (18.20) of the experimental group decreased significantly comparing to pretest scores (25.12). Calculated $\mathrm{t}(\mathrm{t}(18)=7.20)$ is statistically significant at $99 \%$ level. This indicates that the level of mental health of teachers at schools with exceptional students is affected by life skills training.

Table 1. Results of t-test on two groups' mean scores on mental health scale for teachers at schools with normal students.

\begin{tabular}{|c|c|c|c|c|c|c|c|c|}
\hline Variable & Group & $\mathrm{N}$ & Post-test & Pre-test & SD & $\mathrm{t}$ & df & sig \\
\hline \multirow{2}{*}{ Resilience } & Experiment & 30 & 173.17 & 160.12 & 6.20 & \multirow{2}{*}{10.35} & \multirow{2}{*}{58} & \multirow{2}{*}{0.012} \\
\hline & Control & 30 & 162.02 & 164.73 & 2.37 & & & \\
\hline
\end{tabular}

Table 2. Results of t-test on two groups' mean scores on mental health scale for teachers at schools with exceptional students.

\begin{tabular}{ccccccccc}
\hline Variable & Group & $\mathrm{N}$ & Post-test & Pre-test & SD & t & df & sig \\
\hline \multirow{2}{*}{ Resilience } & Experiment & 10 & 169.19 & 152.08 & 17.11 & & \multirow{2}{*}{18.12} & 0.000 \\
& Control & 10 & 154.41 & 153.73 & 1.72 & & & \\
\hline
\end{tabular}

Table 3. Results of t-test on two groups' mean scores on mental health scale for teachers at schools with normal students.

\begin{tabular}{ccccccccc}
\hline Variable & Group & $\mathrm{N}$ & Post-test & Pre-test & $\mathrm{SD}$ & $\mathrm{t}$ & $\mathrm{df}$ & $\mathrm{sig}$ \\
\hline \multirow{2}{*}{ Resilience } & Experiment & 30 & 16.73 & 22.60 & 1.88 & & & \\
& Control & 30 & 24.40 & 19.53 & 3.16 & 2.37 & 58 & 0.021 \\
& & & & & &
\end{tabular}

Table 4. Results of t-test on two groups' mean scores on mental health scale for teachers at schools with exceptional students.

\begin{tabular}{ccccccccc}
\hline Variable & Group & $\mathrm{N}$ & Post-test & Pre-test & SD & sig & \\
\hline \multirow{2}{*}{ Resilience } & Experiment & 10 & 18.20 & 25.12 & 4.12 & 7.20 & 18 \\
& Control & 10 & 23.45 & 22.12 & 1.12 & 0.002 \\
\hline
\end{tabular}




\section{Conclusions}

The results indicated the positive effect of life skills training on mental health of teachers at schools with normal students and teachers at schools with exceptional students, i.e., the more the life skills training to teachers at schools with normal students and teachers at schools with exceptional students, the less their mental health scores would be. Data analysis using t-test indicated that the more the life skills training to teachers at schools with normal students and teachers at schools with exceptional students, the less their mental health scores would be (low scores on mental health questionnaire was associated with high mental health). Other research studies also confirm the above results. Bo et al. [6], examining the quality of life among rural migrants in cities, conclude that teaching life skills to immigrants before the migration, with a focus on efficient coping skills, improves their quality of life and mental health (Momeni Mehmooee, Teimuri and Rahmanpour [12]). Haghighi et al. [17] state that teaching life skills and strategies to cope with mental pressure reduces students' anxiety, insomnia and depression.

The results also indicated the positive effect of life skills training on resilience of teachers at schools with normal students and teachers at schools with exceptional students, i.e., the more the life skills training to teachers at schools with normal students and teachers at schools with exceptional students, the higher their resilience scores would be. Data analysis using t-test indicated that the more the life skills training to teachers at schools with normal students and teachers at schools with exceptional students, the less their mental health scores would be. Other research studies also confirm the above result. Makvandi (2007) studied the influence of life skills education on the youth's level of resilience and found a positive relationship between life skills training and resilience. Fathi et al. [1] find that life skills training causes improved self-esteem and resilience among adolescents and that assertiveness and decisive behavior are two important factors to improve resilience. The result is also consistent with Matsuda and Schiyama (2006), Koupiki (2005) and Arjmandi (2003).

Due to the increasing changes and complexity of society and developing social relations, preparing individuals to deal with difficult situations seems necessary. Therefore, psychologists emphasize life skills training in order to prevent mental illnesses and social abnormalities.

Life skills training is referred to as a series of abilities which bring about positive and useful adaptation. Such abilities allow the individual to accept his social responsibilities and deal with both his own and others' needs, expectations and problems logically. Healthy intimate relationships with other people create solace, comfort and trust.

\section{References}

[1] Fati, L., Motabi, F., Mohammadkhani, Sh., Bolahri, J. and Kazemzadeh Otofi, M. (2006) Life Skills Training for Students: Tutor Handbook. Danjeh Publication, Tehran.

[2] Ganji, H. (2001) Mental Health. Arasbaran Publication, Tehran.

[3] Milanifar, B. (1999) Mental Health. Ghomes Publication, Tehran.

[4] Samani, S., Jokar, B. and Sahragard, N. (2007) Resiliency, Mental Health and Life Satisfaction. Iran Journal of Psychiatry and Clinical Psychology, 50, 541-563.

[5] Bob, L. and Roisin, D. (2010) Using Podcasts to Support Communication Skills Development: A Case Study for Content Format Preferences among Postgraduate Research Students. Computers \& Education, 54, 962-971. http://dx.doi.org/10.1016/j.compedu.2009.09.031

[6] Bo, W., Li, X.M., Bonita, S. and Xiaoyi, F. (2010) The Influence of Social Stigma and Discriminatory Experience on Psychological Distress and Quality of Life among Rural-to-Urban Migrants. China Social Science \& Medicine, in Press, Corrected Proof, Available Online 27 March.

[7] Martin, I. and Jones, D. (2009) Exploring the Life Skills Needs of British Athletes. Psychology of Sport and Exercise, 10, 159-167.

[8] Turner, N.E., Macdonald, J. and Somerset, M. (2008) Life Skills, Mathematic All Reasoning and Critical Thinking: Curricula for Prevention of Problem Gambling. Journal of Gambling Studies, 24, 27-29.

[9] Tuttlejane, C.-H.N. and Bob, L. (2006) Posit Adolescent Life Skill, Training for High-Risk Teen Results of a Group Intervention.

[10] Johnson, O. and Johson, R. (2000) Learning Together and Alone: Cooperative Competitive, and Individualistic Learning. Allyn and Bacon, Boston.

[11] Harter, S. (1998) The Development of Self-Representation. In: Damon, W. and Eisenberg, N., Eds., Handbook of Child 
Psychology, 5th Edition: Volume 3, Social, Emotional, and Personality Development, John Wiley \& Sons, Chichester, 518-553.

[12] Rahmanpour, M., Teimori, S. and Momeni Mehmooee, H. (2011) Examining the Effects of Life Skills Training on Mental Health and Self-Esteem of Fifth-Grade Female Elementary Students. Journal of New Thoughts on Education, 6 , 102-112.

[13] Pourseyed, R., Habibolahi, S. and Faramarzi, S. (2010) The Effectiveness of Life Skills Training on Adaptation of Blind and Visually Impaired Students. Journal of Educational Strategies, 3, 7-11.

[14] Jalili Abkenar, S. (2010) Teaching Social Skills to Students with Impaired Hearing. MA Thesis, University of Social Welfare and Rehabilitation Sciences, Tehran.

[15] Sajedi, S., Attashpour, H., Kamkar, M. and Samsam Shariiat, M.R. (2009) The Impact of Life Skills Training on Interpersonal Relations and Self-Esteem and Self-Expression of Blind Girls. Knowledge and Research in Applied Psychology, 11, 96-102.

[16] Ahadi, B., Mirzaee, P., Narimani, M. and Abolghasemi, A. (2008) The Impact of Social Problem Solving Training on Social Adjustment and Academic Performance of Shy Students. Research on the Exceptional Children, 33, 193-202.

[17] Haghighi, J., Mosavi, M., Mehrabzadeh Honarmand, M. and Bashbalide, K. (2006) Examining the Effects of Life Skills Training on Mental Health and Self-Esteem of First Grade Female High School Students. Journal of Educational Sciences of Chamran University, 13, 61-78. 